\title{
In the fast lane
}

\section{Over the past decade or so, China has turned into a land of opportunity for science. We are keen to witness first hand how the geoscience landscape continues to unfold.}

China has overtaken both Europe and the US in terms of its carbon dioxide emissions ${ }^{1}-$ sadly, still a sign of economic strength. The country is also climbing up the ranks of places producing high-impact scientific output, and the Earth sciences are no exception. The Nature INDEX (https://www.natureindex. $\mathrm{com} /$ ) - which charts the changing landscape of high-quality research - revealed a $24 \%$ increase in the number of China-based authors in top Earth and environmental sciences journals. China is now second only to the United States of America. It was always unlikely that such an upheaval in the global pecking order would go without some discontent among the long-established scientific powerhouses. Indeed, we have anecdotally — heard some grumbling at conferences; for example, about a lack of participation in peer review, and lower levels of innovation. We at Nature Geoscience are excited to soon see the geoscience research landscape of East Asia for ourselves: our editor Rebecca Neely is now based in Shanghai.

In terms of manuscript submissions to Nature Geoscience, the proportion of papers with first authors based in China has risen steeply, from 5\% in our launch year (2008) to $15 \%$ in 2016 . Over the same period, the accept rate among papers from Chinese institutions has risen, too, so the threefold increase in the share of submissions has translated into more than a tripled share of published articles. This is against the backdrop of our ever-tightening editorial standards, as submission numbers have risen over the years ${ }^{2}$, and our overall accept rate has dropped from $12 \%$ in 2008 to $7 \%$ in 2016 . The ratio of accepted to submitted papers from China is still lower than what is typical for Europe or the US. But, the gap is closing - accept rates have been declining for most countries with a sufficiently high number of submissions to exclude undue influence of one or two chance publications.

This success is probably rooted in strong governmental support. China is committed to expanding science education and funding. In 2010 , over $40 \%$ of Chinese students studied science, technology, engineering or mathematics at undergraduate level, compared with just 16\% in the United States, and China now awards more doctoral degrees in science than the USA ${ }^{3}$. With a population of over 1.3 billion people, China's institutions have a formidable population of scientifically

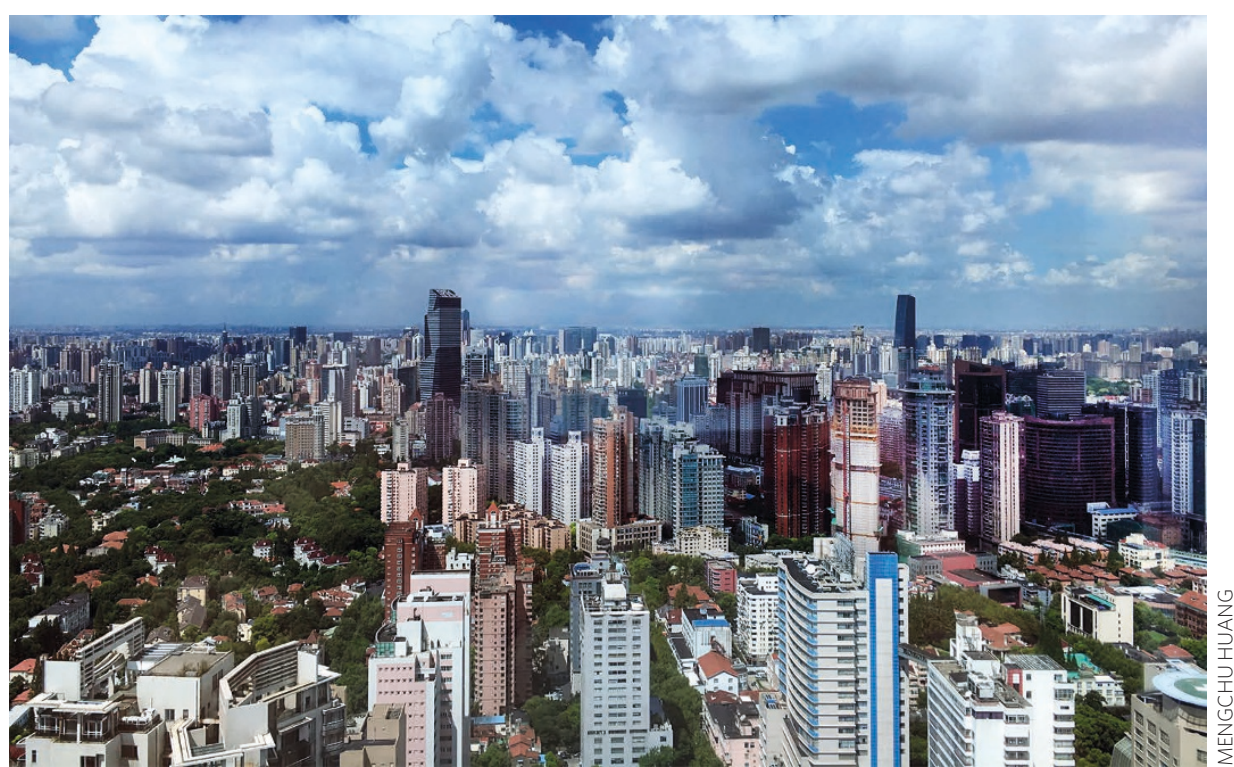

Views across the Shanghai skyline from the Nature Research office.

trained graduate students to choose their post-docs from. And the latest five-year plan, which sets research and development investment at $2.5 \%$ of GDP and plans for the removal of bureaucratic barriers ${ }^{4}$, suggests China's commitment to supporting high-level research is only going to strengthen further.

However, these promising statistics do not seem to have translated into a perception among western geo scientists of China as a scientific powerhouse. Instead, the conversations Nature Geoscience editors have had at conferences suggest reservations. Genuine issues have been raised; for example, China's scientists currently do not participate in peer review at a level proportionate to their authorship. This excludes them to some degree from the broader discussion of the latest research that science thrives on ${ }^{5}$. It also means that there is a subtle skew in the role of China-based scientists in the publishing world: they are more often in a position of being judged than of judging - which could affect their own perceptions and those of others.

The under-representation of reviewers based in China can be partially attributed to an effect of inertia in editors and scientists getting to know to the Chinese scientific community, because the rise of science from China has been so fast. In addition, the financial incentive to publish ${ }^{6}$ may be leading to more submissions than would otherwise be attempted. The first will settle with time and conscious effort. As for the second, the pros and cons for will need to be assessed within China. Full participation of Chinese researchers in peer review needs to be addressed by the scientific community, inside and outside of China.

Perceptions of a lack of innovation are not supported by the statistics of highimpact papers, at least not for the top institutions. We are looking forward to exploring the innovation potential at China's research laboratories.

We continue to argue that a more diverse community of geoscientists will be able to solve a more diverse range of problems ${ }^{7}$. We are curious about the perspective from China.

\section{References}

1. Friedlingstein, P. et al. Nat. Geosci. 7, 709 (2014).

2. Nat. Geosci. 6, 1 (2013)

3. Xie, Y., Zhang, C. \& Lai, Q. Proc. Natl Acad. Sci. USA 111, 9437-9442 (2014).

4. McLaughlin, K. Science is a major plank in China's new spending plan. Science (7 March 2016)

5. Nat Geosci. 10, 615 (2017).

6. Nature 547, 137 (2017).

7. Nat. Geosci. 9, 797 (2016) 